\title{
Dangerous Driving Behaviors of Intra-city and Intercity Bus Drivers: Is There any Difference?
}

\author{
Maryam Abdi' ${ }^{\text {iD }}$, Shiraze Arghami2,* iD , Ramadan Fallah ${ }^{3}$, Hamid Shahbazi ${ }^{4}$ \\ ${ }^{1}$ MSc of Department of Occupational health and safety engineering, School of Public Health, Student Research Committee, \\ Zanjan University of Medical Sciences, Zanjan, Iran \\ ${ }^{2}$ Associate Professor, Department of Occupational Health and Safety Engineering, School of Public Health, \& Research \& \\ Technology Group of Road Traffic Injury Prevention (RTIP) Zanjan University of Medical Sciences, Zanjan, Iran \\ ${ }^{3}$ Associate Professor, Department of Biostatistics, School of Public Health, Zanjan University of Medical Sciences, Zanjan, \\ Iran \\ ${ }^{4}$ BSc, Department of Occupational Health and Safety Engineering, Student Research Committee, Zanjan University of \\ Medical Sciences, Zanjan, Iran \\ * Corresponding Author: Shiraze Arghami, Department of Occupational Health and Safety Engineering, School of Public \\ Health, \& Research \& Technology Group of Road Traffic Injury Prevention (RTIP) Zanjan University of Medical Sciences, \\ Zanjan, Iran.Email: arghami@zums.ac.ir
}

Received: $23 / 09 / 2020$

Accepted: 16/01/2021

How to Cite this Article:

Abdi M, Arghami S, Fallah R, Shahbazi H. Dangerous Driving Behaviors of Intra-city and Intercity Bus Drivers: Is There any Difference? $J$ Occup Hyg Eng. 2021; 8(1): 1-9 DOI: 10.29252/johe.8.1.1

\begin{abstract}
Background and Objective: Bus drivers, the same as other drivers, are prone to unsafe behavior, and accidents are associated with driver's risky behavior. Moreover, traffic accidents are different in intra-city and intercity routes, which can be at least partly due to the driver's behavior. Therefore, this study aimed to compare the dangerous driving behavior of intra-city and intercity bus drivers.

Materials and Methods: This descriptive and analytical study was performed on 107 intra-city and 99 intercity bus drivers in the city of Zanjan, Iran, using demographic characteristics form and the Dula Dangerous Driving Index. Eventually, the collected data were analyzed in SPSS software (version19) through a t-test, chi-square test, and linear regression. The p-value less than 0.05 was considered statistically significant.

Results: The mean weekly working hours of intra-city bus drivers are significantly higher than those of intercity bus drivers $(\mathrm{P}<0.05)$. Moreover, the mean of the dangerous driving index and its sub-scales, except for aggressive driving, were higher in intra-city bus drivers, compared to intercity bus drivers $(\mathrm{P}<0.05)$. In addition, the weekly working hours variable had a negative impact on the risky driving score in the intra-city driving routes; however, it had a negative impact on the emotional/cognitive driving subscale and a positive impact on the drunk driving subscale in the intercity driving rout $(\mathrm{P}<0.05)$.

Conclusion: Despite the lower number of fines and deaths on intra-city routes, it is necessary to take more serious control measures for the risky behaviors of bus drivers. These include developing intervention programs to manage bus drivers' working hours in order to reduce fatigue and raise drivers' awareness for less risky driving behaviors.
\end{abstract}

Keywords: Dangerous Driving; Dula Dangerous Driving Index; Intercity Bus Driver; Intra-City Bus Driver; Risky Driving; Traffic 
doI: $10.29252 /$ johe.8.1.1

\title{
راندكى خطرناك در راندكان اتوبوس درون و بين شهرى: آيا تفاوتى وجود دارد؟
}

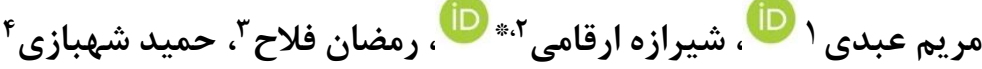

' دانشجوى كارشناسى ارشد گروه مهندسى بهداشت حرفهاى، دانشكده بهداشت، دانشكاه علوم يزشكى زنجان، زنجان، ايران

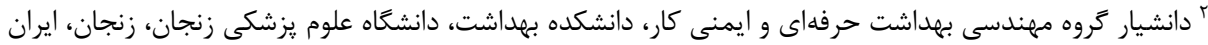

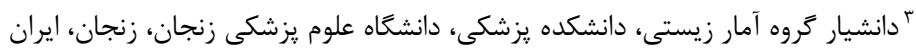

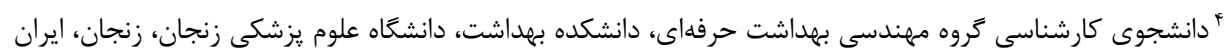

* * نويسنده مسئول: شيرازه ارقامى، كروه مهندسى بهداشت حرفهاى و ايمنى كار، دانشكده بهداشت، دانشكاه علوم يزشكى زنجان، ايران. ايميل: arghami@zums.ac.ir

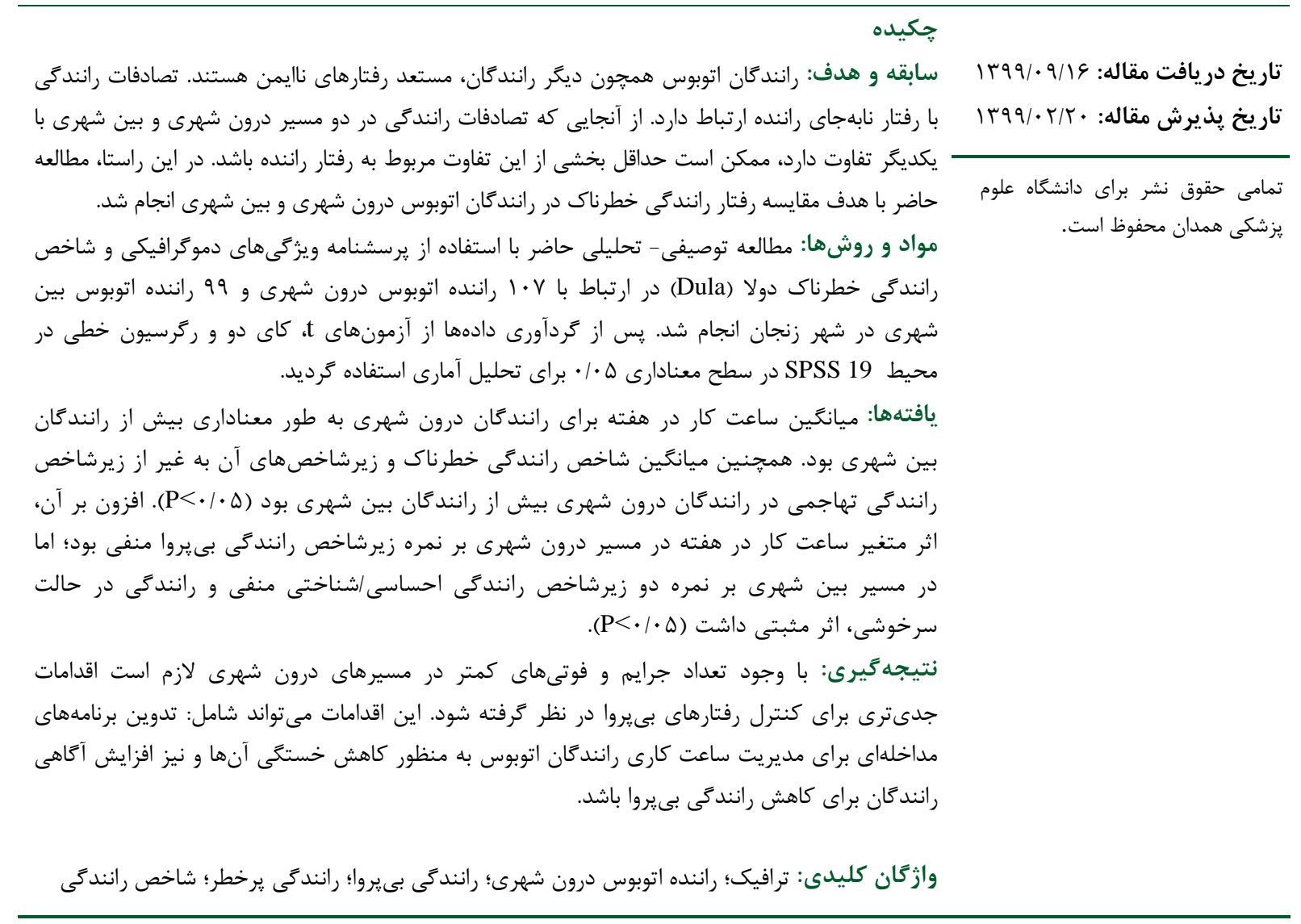

بيمارىها را به خود اختصاص داده [ب] و دومين علت مرگ مع باشند [l].

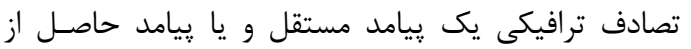

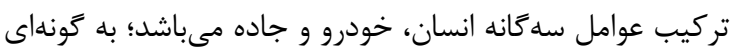

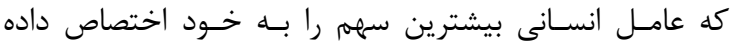

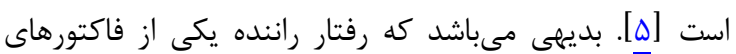

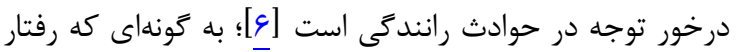

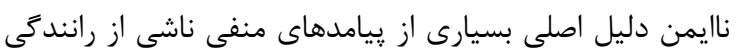

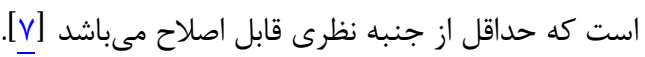

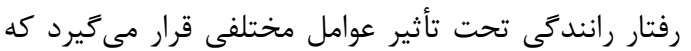

رانندگى از جمله فعاليتهاى رايج در تمام دنيا است. اين

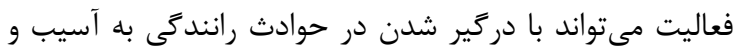


شايعترين علل مرى در دنيا مىباشد [1]]. زَزارش سازمان

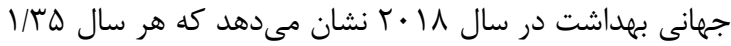

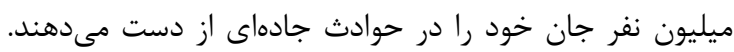
همجنين مشخص شده است كه صدمات ناشى از ترافيك جادهاى، هشتمين عامل مرگ در در تمام گروههاى سنى

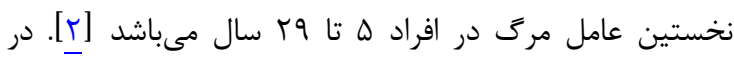

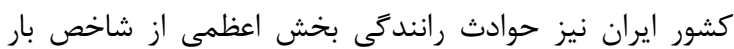




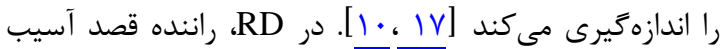

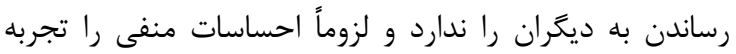

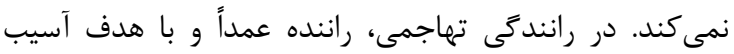

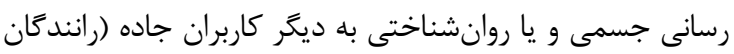

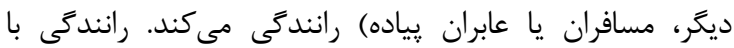

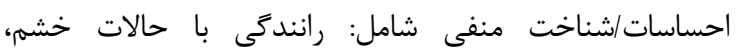
سرخوردىى و نشخوار فكرى، غم و اندوه، افسردىى، حسادت و و

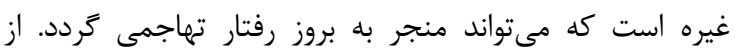
آنجايى كه برخى از افراد توانيى كاربرد استراتزىهاى كنائ كنترل

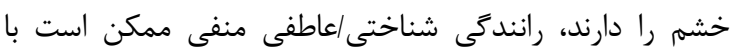

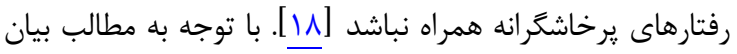

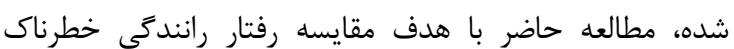
راندكان اتوبوسهاى درون شهرى (شركت واحد) و بين شهرى باليا

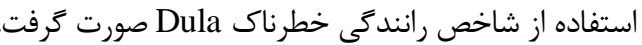

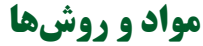 روش اجرا مشاركت كنندكان}

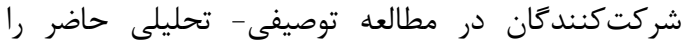

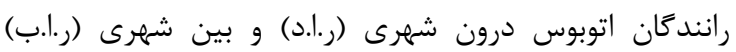

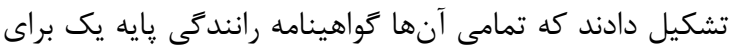
رانندگى با اتوبوس داشتند و در سه سال متوالى اخير، راننده

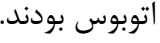
با استفاده از مطالعات مشابه و رابطه كوكران با ضريب اطمينان ه9 درصد و خطاى نمونه ميرى له درصد، حجم نمونه

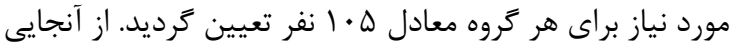

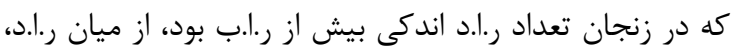

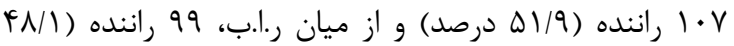
درصد) به روش نمونه קايانه شركت واحد اتوبوسرانى و پايانه مسافربرى شهر زدرى زنجان

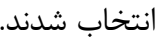

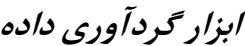

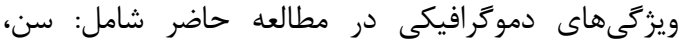
جنس، سطح تحصيلات، سابقه كار رانندگى با اتوبوس و تعداد

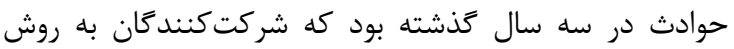

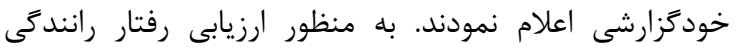

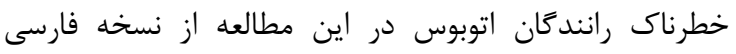
شاخص رفتار رانندگى خطرناك (DDDI) Dula) استفاده شد.

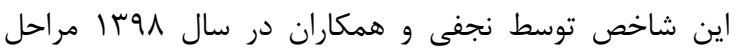

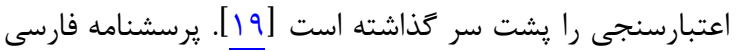

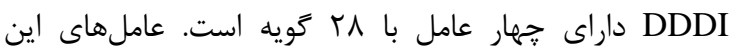

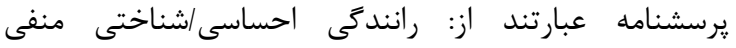
(NCED)
به طور عمده مىتوان به عوامل انسانى، محيط و وسايل نقليه

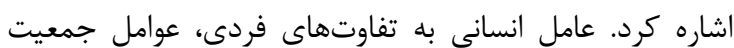

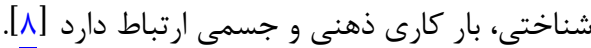

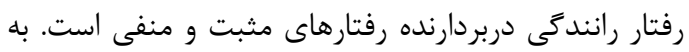

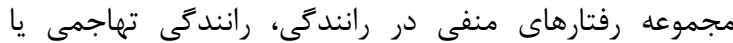

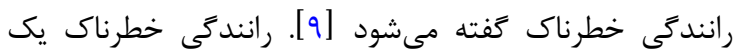

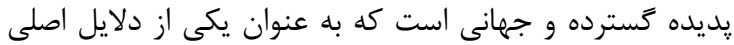

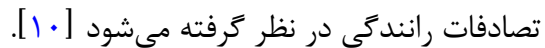

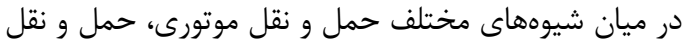

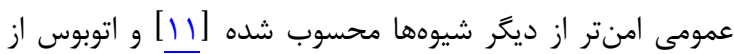

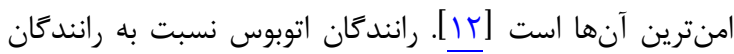

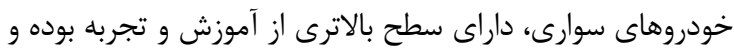

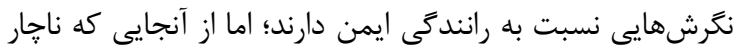

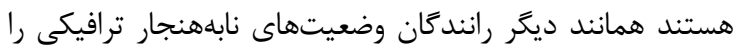

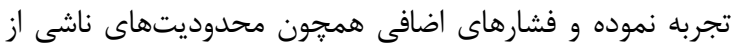

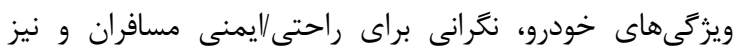

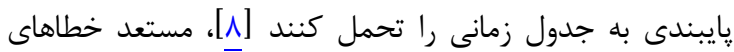

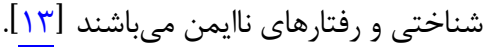

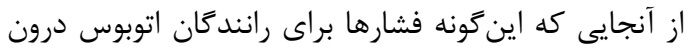

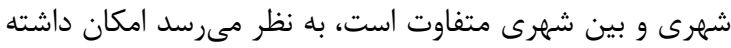

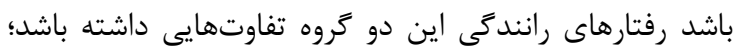

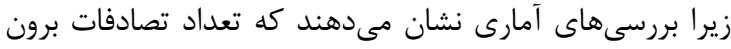

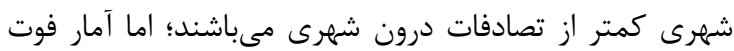
در تصادفات درون شهرى بسيار كمتر از تصادفات برون شهرى دمرى دمادي

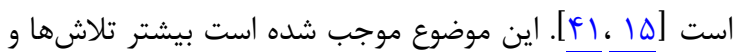



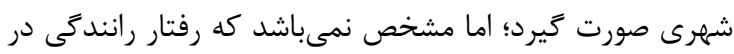

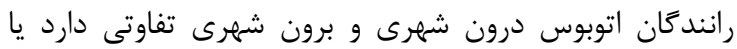

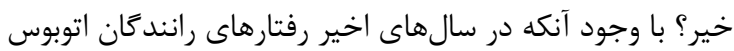
مورد توجه يُروهشكران قرار گرفته است؛ اما به اين موضوع كمتر يرداخته شده است.

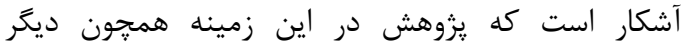

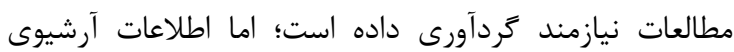

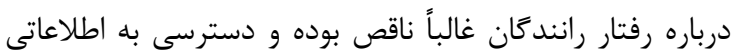

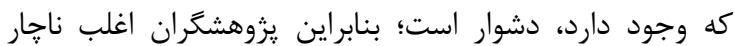

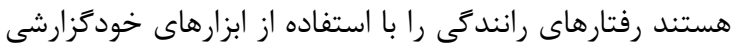

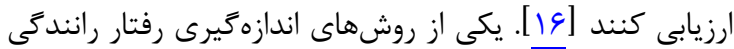

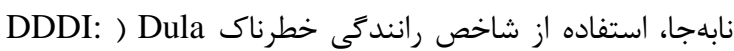

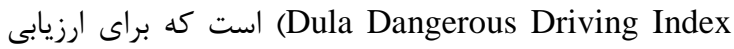
تمايل فرد به رانندگى خطرناك به كار مىرود. اين شاخص در

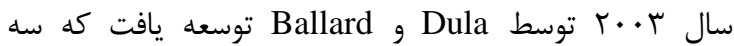
ساختار متمايز رانندگى تهاجمى (AD: Aggressive Driving)،

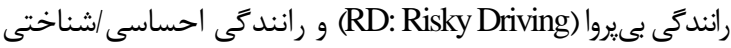
منفى (NCED:NegativeCognitive/EmotionalDriving) 
گروه ر.ا.د و ر.اب ارائه شده است. همانطور كه مشاهده

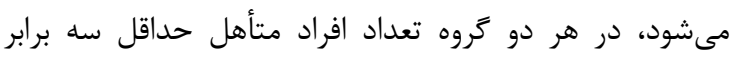

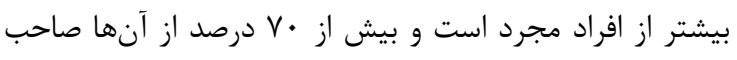

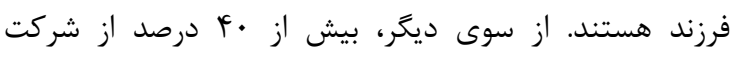

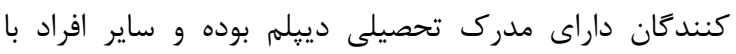

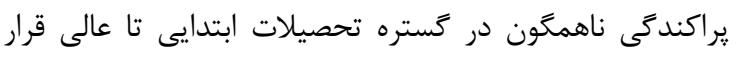

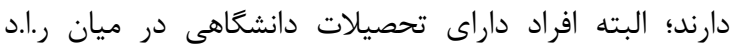
بيشتر مى باشد. نتايج اين جدول نشان مى دهند كه دو گروه از نظر تأهل، تعداد فرزند و ميزان تحصيلات، تفاوت آمارى معنادارى ندارند.

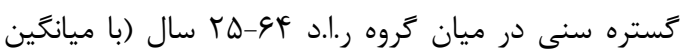
r

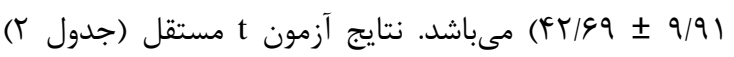
حاكى از آن هستند كه اين اختـلاف از نظر آمارى معنـادار

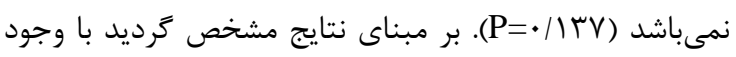

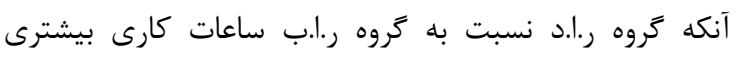

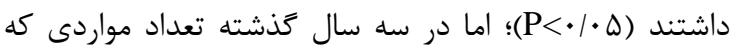

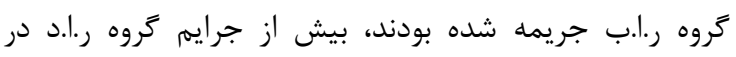

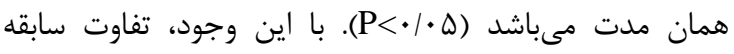

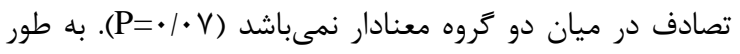

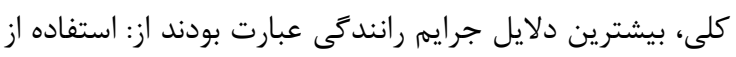

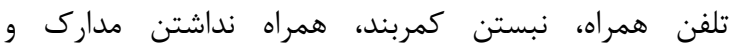
كواهىنامه، نقص فنى، سرعت، معاينه فنى، سوار كردن مسافر

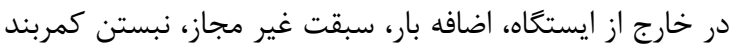
توسط مسافر و غيره.

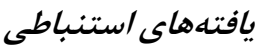

نتايج حاصل از مقايسه نمرات مربوط به شاطئه شاخص رانندگى

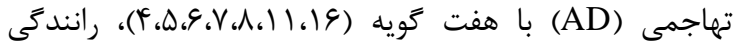
بى يروا (RD) با • (

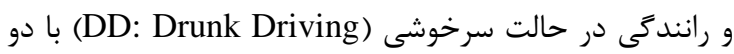

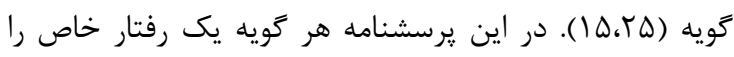

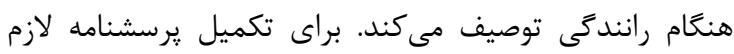

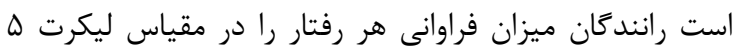

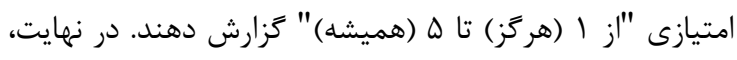

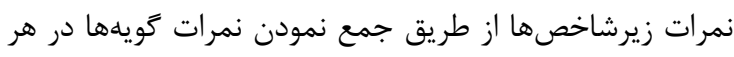

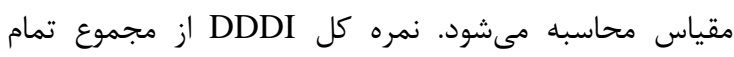

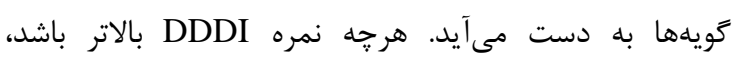
نشاندهنده رفتارهاى خطرناى بيشترى در رانندگى است.

\section{تجزيه و تحليل دادهها}

ابتدا نرمال بودن توزيع دادههاى كردآورى شده بهادها به وسيله

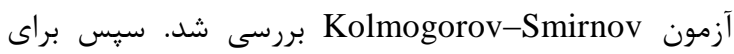
تحليل دادهها از آزمون t مستقل، آزمون كاى دو (chi-square)

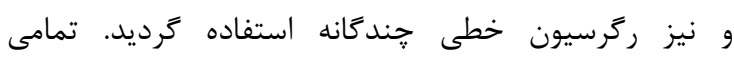

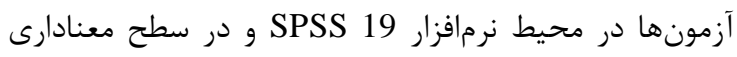

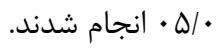

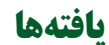

نتايج آزمون Kolmogorov-Smirnov نشان دادند كه دادههاى گردآورى شده از توزيع نرمال برخوردار بوده و مىتوان از روشهاى آمار پارامترى براى تحليل دادهها استفاده كرد.

يافتههاى توصيفى در جدول ا توزيع فراوانى متغيرهاى تأهل، تعداد فرزند و

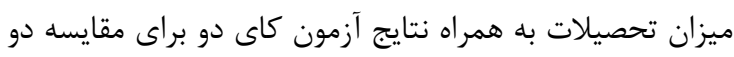

جدول ا: مقايسه توزيع فراوانى مشخصات فردى راندكًان درون شهرى و بين شهرى

\begin{tabular}{|c|c|c|c|c|c|c|}
\hline \multirow[t]{4}{*}{ سطح معنادارى } & \multicolumn{4}{|c|}{ كروههاى رانندَان } & & \multirow{4}{*}{ ويزَى هاى فردى } \\
\hline & \multicolumn{2}{|c|}{ بين شهرى } & \multicolumn{2}{|c|}{ درون شهرى } & & \\
\hline & درصد & تعداد افراد & درصد & تعداد افراد & & \\
\hline & FN/I & 99 & $01 / 9$ & $1 \cdot V$ & & \\
\hline \multirow[t]{2}{*}{$\cdot \mid i v$} & $19 / \pi$ & 19 & $1 T / 9$ & Ir & مجرد & \multirow{2}{*}{ وضعيت تأهل } \\
\hline & $\wedge r / \Lambda$ & 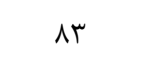 & $\Lambda V / \mathcal{F}$ & 9 . & متأهل & \\
\hline \multirow[t]{4}{*}{$\cdot / 49$} & $r T / r$ & Tr & $r q / 1$ & $r$. & صفر & \multirow{4}{*}{ ع عداد فرزند } \\
\hline & $|f /|$ & $1 f$ & $19 / 4$ & $r \cdot$ & يك & \\
\hline & $r \varepsilon / T^{c}$ & rद & re & r & دو & \\
\hline & $r V / r$ & TV & $19 / 0$ & $r \cdot$ & سه و بيشتر & \\
\hline \multirow[t]{4}{*}{$\cdot 1 \cdot \wedge$} & $I V / T$ & IV & $1 \cdot / V$ & 11 & ابتدايى & \multirow{4}{*}{ ييزان تحصيلات } \\
\hline & $r V / \mathcal{A}$ & rv & ru/l & rt & سيكل & \\
\hline & $F T / F$ & Fr & $F \Delta / 9$ & FV & دييلم & \\
\hline & r & r & $I T / V$ & ir & ليسانس & \\
\hline
\end{tabular}


جدول ז: مقايسه ويزّى هاى فردى و شغلى رانندكان درون شهرى و بين شهرى

\begin{tabular}{|c|c|c|c|c|c|}
\hline \multirow{3}{*}{ سطح معنادارى } & \multicolumn{4}{|c|}{ كروههاى رانندگان } & \multirow{3}{*}{ وآماره } \\
\hline & \multicolumn{2}{|c|}{ بين شهرى } & \multicolumn{2}{|c|}{ درون شهرى } & \\
\hline & انحراف معيار & ميانگين & انحراف معيار & ميانغين & \\
\hline . /ITV & $9 / 91$ & Fr/G9 & $N / F^{2}$ & $f \cdot / V q$ & سن \\
\hline .1199 & $1 / T V$ & $1 / 19$ & $1 / 4$ & $1 / \Delta r$ & فرزند \\
\hline$\cdot / \cdot r$ & $1 / \cdot 1$ & $10 / T \&$ & $V / \cdot 9$ & $11 / D F$ & سابقه كار \\
\hline$\cdot 1 \cdot \cdot \Delta$ & $10 / 99$ & $\Delta \& / \Gamma \Lambda$ & Tr/VA & $\vee \Delta / / \Lambda$ & ساعت كار در هفته \\
\hline$\cdot 1 \cdot \cdot \Delta$ & $T V / l$. & $r / / 8 \Delta$ & $\Lambda / \wedge F$ & f/rg & جرايم رانندَى \\
\hline$\cdot / \cdot V$ & $1 / 1 F$ & $\cdot / 49$ & $1 / \wedge 9$ & $\cdot 191$ & سابقه تصادف \\
\hline
\end{tabular}

مستقل بررسى شده (سن، ميزان تحصيلات و غيره)، تنها

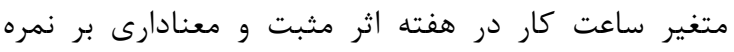

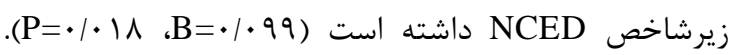

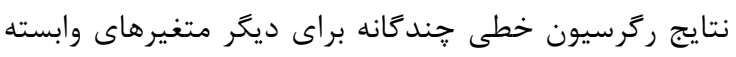

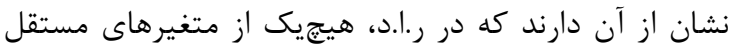

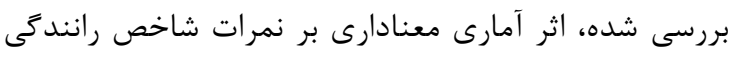

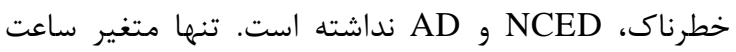
كار در هفته، اثر آمارى منفى و معنادارى بر نمره RD داشته

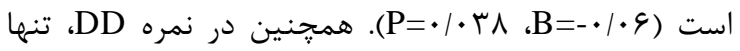

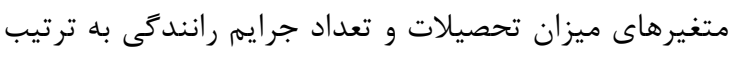

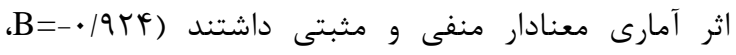
D D

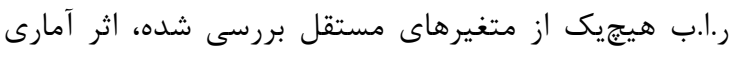

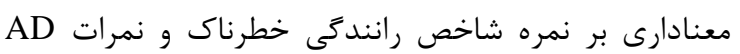

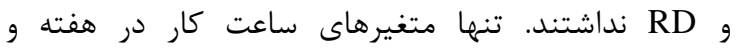

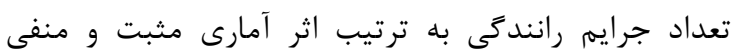

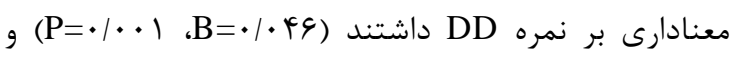
. $(\mathrm{P}=\cdot / \cdot 1 r$ ، $\mathrm{B}=-\cdot / \cdot r \mathrm{r})$
خطرناك و زيرشاخصهاى آن در دو گروه ر.ا.د و ر.اب با

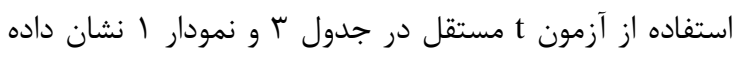
شده است.

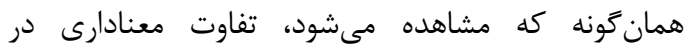

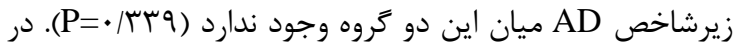

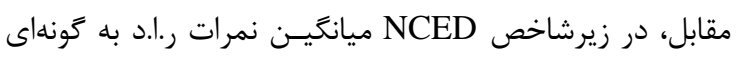

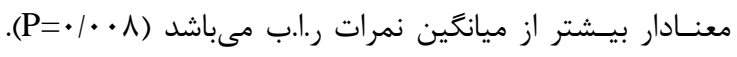

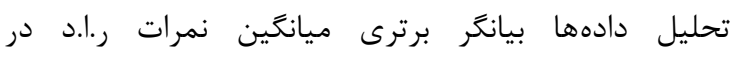

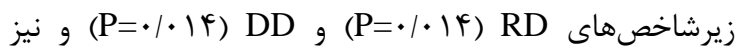

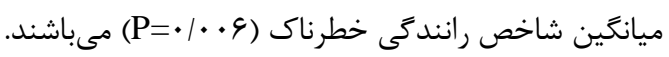



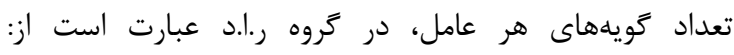
مربوط $\mathrm{AD}=1 / \mathrm{V}$ ، $\mathrm{DD}=1 / 9 \mathrm{RD}=1 / \Delta 9$ ، است. در حالى كه براى گروه ر.ا.ب اين نمرات عبارت هستند از: $\mathrm{RD}=1 / 4), \mathrm{DD}=1 / 4 q$ ، $\mathrm{AD}=1 / 9 r$ ، NCED $=r / \cdot \uparrow$ نتايج يك نمونه از ركرسيون خطى جندكانه براى هريك از متغيرهاى وابسته در جدول أ نشان داده شده است.

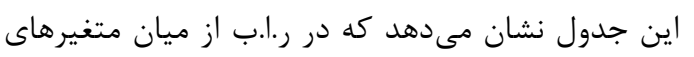

جدول ب: مقايسه ميانكين نمرات شاخص رانندگى خطرناك و زيرشاخصهاى آن در دو گروه

\begin{tabular}{|c|c|c|c|c|c|}
\hline \multirow{3}{*}{ سطح معنادارى } & \multicolumn{4}{|c|}{ كروههاى رانندگًان } & \multirow{3}{*}{ رآماره } \\
\hline & \multicolumn{2}{|c|}{ بين شهرى } & \multicolumn{2}{|c|}{ درون شهرى } & \\
\hline & انحراف معيار & ميانغين & انحراف معيار & ميانگين & \\
\hline$\cdot 1 \cdot 1$ & $g / \pi \mid$ & $\begin{array}{l}\mid N / T Y Y \\
(Y / \cdot Y)\end{array}$ & $9 / 9 \Lambda$ & $\begin{array}{l}r \cdot / V V \\
(T / T /)\end{array}$ &  \\
\hline ( & T/F & $\begin{array}{l}11 / r V \\
(1 / G T)\end{array}$ & $Y / \& V$ & $\begin{array}{l}11 / 9 r \\
(1 / V)\end{array}$ & 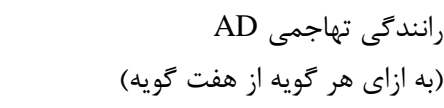 \\
\hline$\cdot 1 \cdot 1 \mathrm{f}$ & $r / 9 \Lambda$ & $\begin{array}{l}\mid f / \cdot \wedge \\
(1 / f \mid)\end{array}$ & $8 / 4$. & $\begin{array}{l}10 / 9 \\
(1 / 09)\end{array}$ & 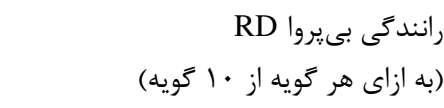 \\
\hline$\cdot 1 \cdot 1 \mathrm{~F}$ & $T / T T$ & $\begin{array}{l}r / q \vee \\
(1 / \uparrow q)\end{array}$ & $r / V I$ & $\begin{array}{l}r / \Lambda r \\
(1 / 9 T)\end{array}$ & 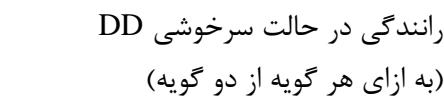 \\
\hline$\cdot 1 \cdot \cdot 9$ & $1 / \Gamma \Lambda$ & $\begin{array}{l}F \& / V V \\
(1 / 9 V)\end{array}$ & $1 / 9 V$ & $\begin{array}{l}\Delta Y / \mathcal{G Y} \\
(I / A Y)\end{array}$ & 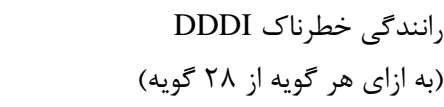 \\
\hline
\end{tabular}


جدول ^ا: ارتباط زيرشاخص رانندگى احساسى/شناختى منفى با متغيرهاى مستقل مطالعه در گروه بين شهرى

\begin{tabular}{|c|c|c|c|c|c|c|}
\hline \multicolumn{2}{|c|}{ فاصله اطمينان هף درصد براى B } & \multirow{2}{*}{ سطح سطادارى } & \multicolumn{2}{|c|}{ ضرايب غير استاندارد } & & \\
\hline كران بالا & كران هايين & & خطاى استاندارد & ضريب B & & \\
\hline$r \cdot / r \wedge \Delta$ & $-\cdot / 0 \cdot 1$ & $.1 \cdot 94$ & $\Delta / T \Delta q$ & $9 / 9 ५ \wedge$ & مقدار ثابت & \\
\hline$\cdot / r V \Delta$ &.$- / 11 r$ & $\cdot / r q$. & . & $.|| r \mid$ & سن - & \\
\hline $1 / 149$ & $-Y / \Delta V F$ & q/FFF & $\cdot / 9 r V$ & $-\cdot / V I T$ & ميزان تحصيلات & \\
\hline $1 / 7 \wedge 9$ & $-1 / \Delta T H$ & $\cdot 11999$ & $\cdot / V \cdot \Lambda$ & $-\cdot / 11 \mathrm{~V}$ & ت تعداد فرزند & \\
\hline$\cdot / 1 \wedge \Delta$ & $-\cdot / T F D$ & $\cdot / V \wedge \Delta$ & $\cdot 11 \cdot 1$ & $-\cdot / \cdot r \cdot$ & سابقه كار & شاسى /شناختى \\
\hline$\cdot / 11$ & $\cdot / \cdot 1 \mathrm{~V}$ & $\cdot 1 \cdot 11$ & $\cdot|\cdot|+\mid$ & .1 .99 & ساعت كار در هفته & \\
\hline$\cdot / \cdot r q$ & -.1 .94 & $\cdot 1909$ & $\cdot 1 \cdot r \Delta$ & $-\cdot \cdot \cdot 11$ & جرايم راندَى & \\
\hline$\cdot|\Delta 9|$ & $-1 / A T \Delta$ & $\cdot / r 9 \Delta$ & $\cdot 19 . \cdot$ & - . & سابقه تصادف & \\
\hline
\end{tabular}

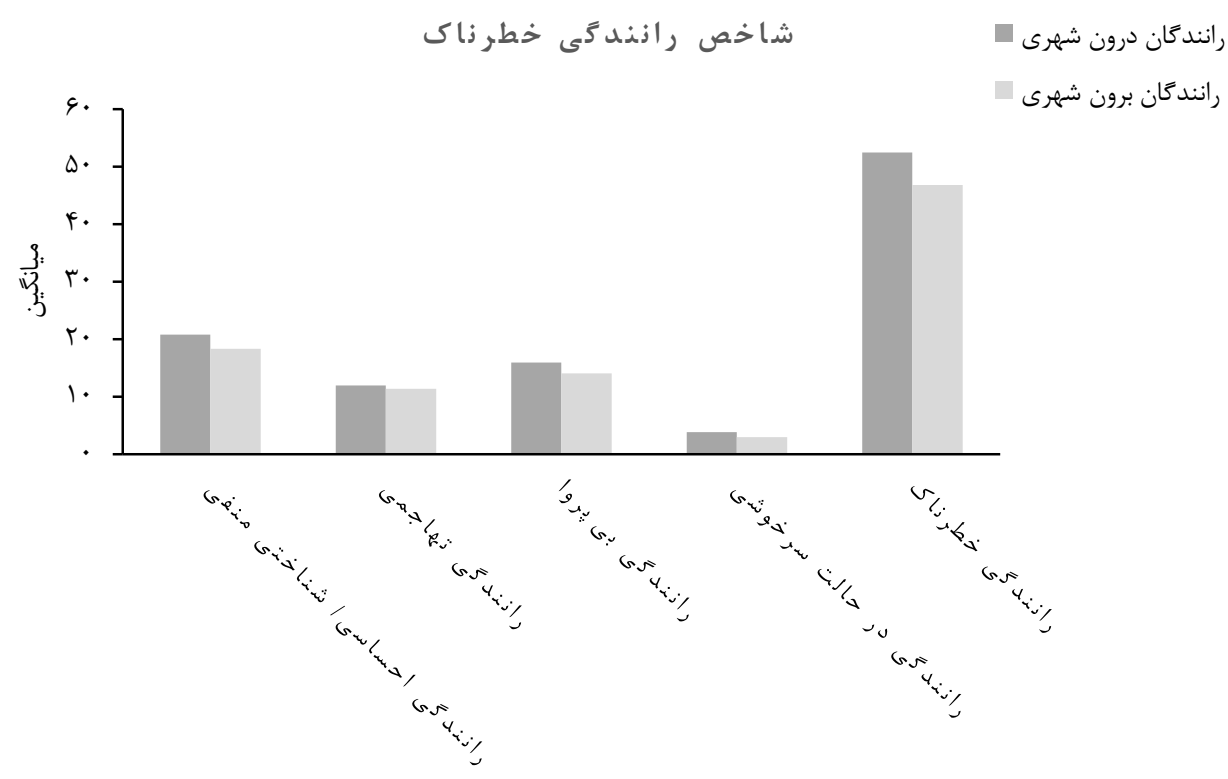

نمودار 1: مقايسه ميانگين نمرات شاخص رانندكى خطرناك و زيرشاخصهاى آن در دو كروه

مطالعه Hernandez و همكاران (19 • (Y) رفتار رانندگى افراد

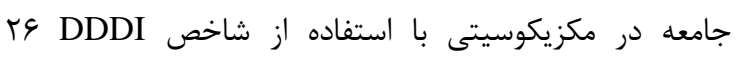

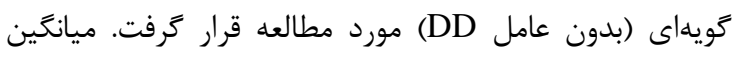

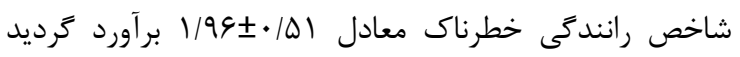

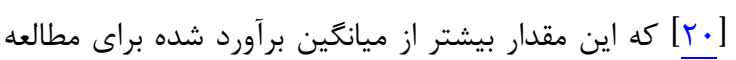

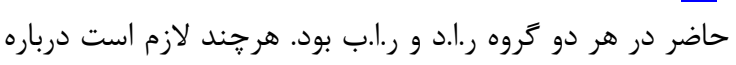

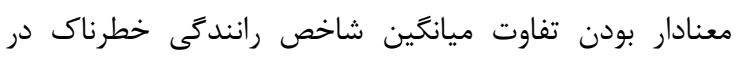

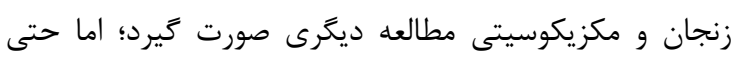

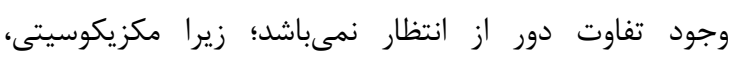

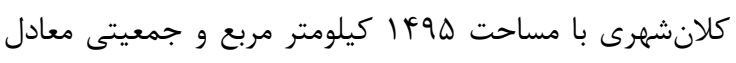

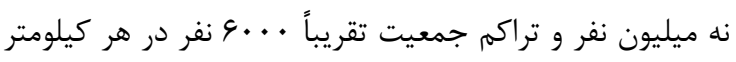

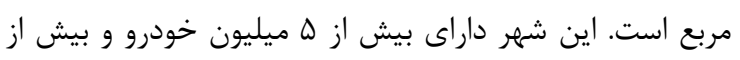

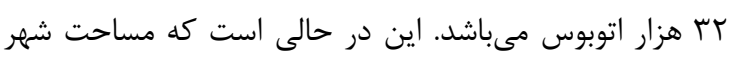

هدف از يزوهش حاضر، مقايسه رفتار رانندگى خطرناك

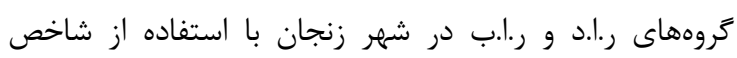

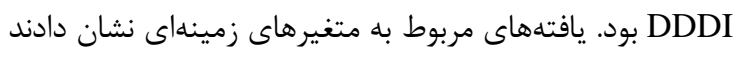
كه اين دو گروه از نظر سن، تعداد فرزند، تأهل، ميزان

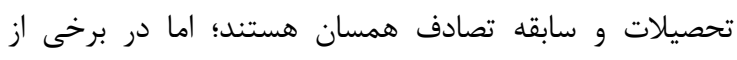
جنبههاى مربوط به كار مانند ميانخين ساعت كار در هفتها،

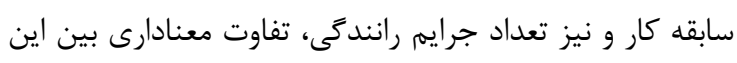
دو كروه وجود ندارد.

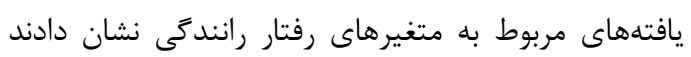

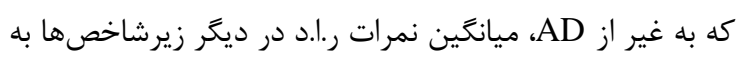
شكل معنادارى بيشتر از ميانكين نمرات ر.ا.ب بوده است. دئن ديخر

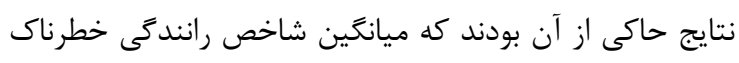

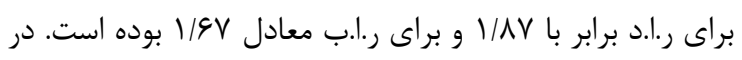


در ر.ا.د بيشتر از ر.ا.ب بود. شايد يكى از دلايل اين تفاوت، وجود

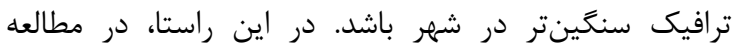
RenHu شغلى يراسترسى را تحمل مىكنند. اين رانندكان با وسايل

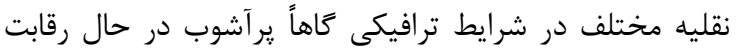

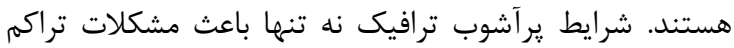

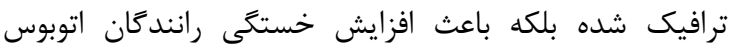

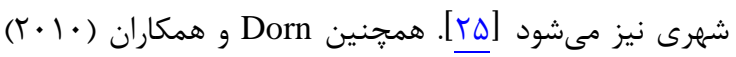
در يزوهش خود بيان نمودند كه رانندگى اتوبوس به دليل تقابل

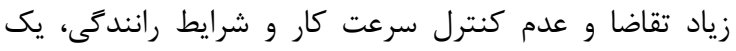

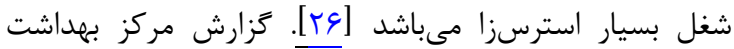

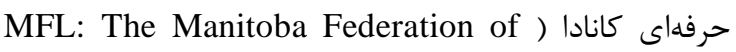

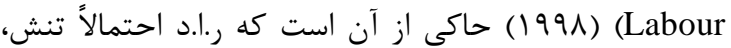

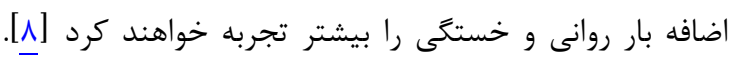

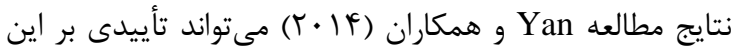

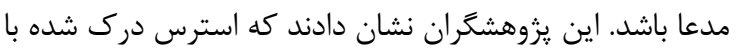

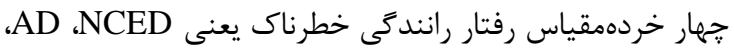
RD و RD ارتباط مثبت و معنادارى دارد [rVD]

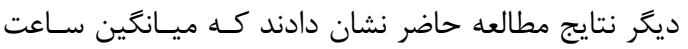

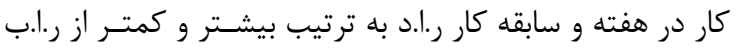

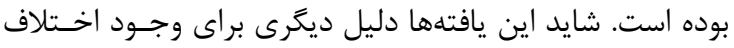

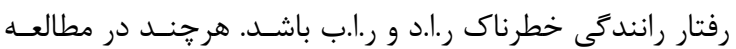
حاضر در مسير درون شهرى، ساعت كار در هفته تنها بـر نمـره

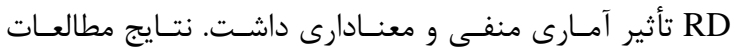

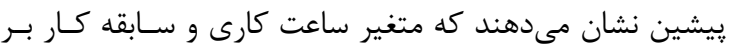

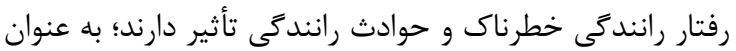

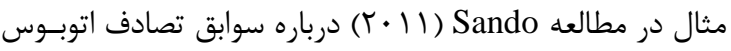

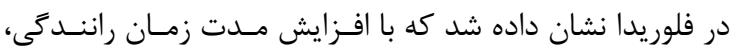

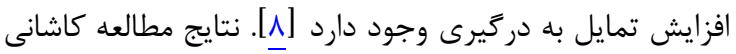

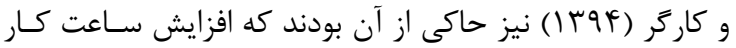

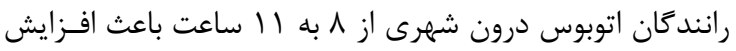

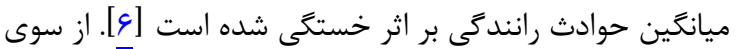

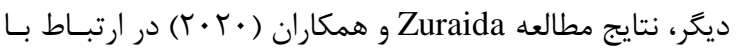
رانندكان اتوبوس بين شهرى بر اين مهرم تأكيـــ دارد كـهـ زمــان

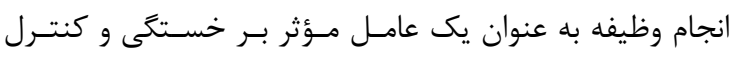

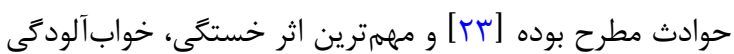

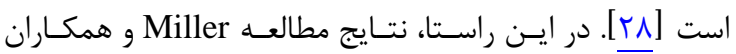

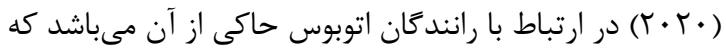

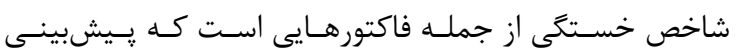

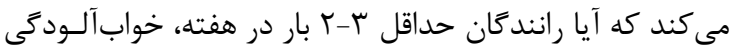

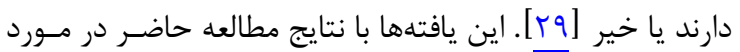

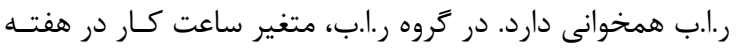

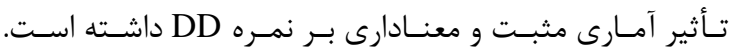

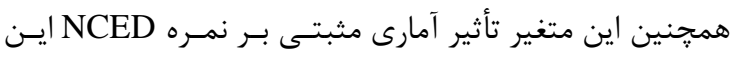

زنجان معادل هوا كيلومتر مربع و جمعيت آن حدود • PV هزار

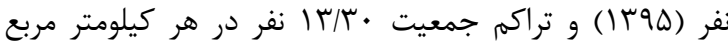

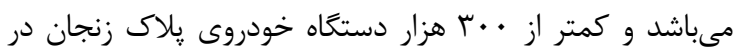

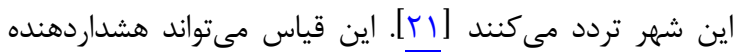

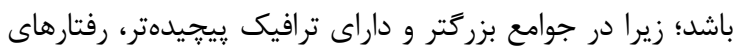

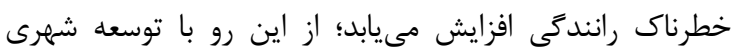

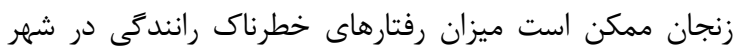

زنجان از ميزان رفتارهاى مشابه در مكزيكوسيتى ييشى كير ميرد.

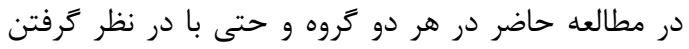

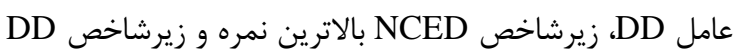

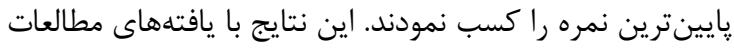
و و همكاران (هeina

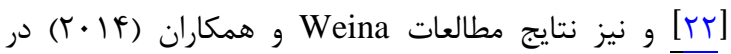



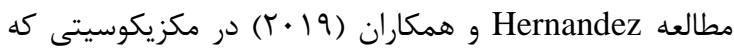
عامل DD در آن در نظر كرفته نشده بود، بيشترين ميانخين

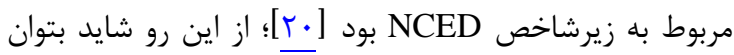

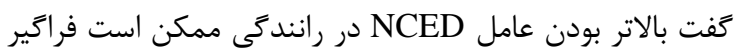
باشد؛ بنابراين بهتر است براى كاهش تصادفات، اين عامل

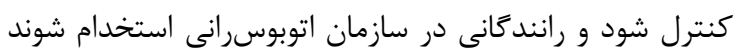

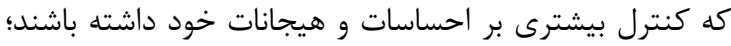

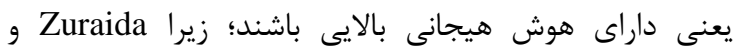
Bahtiar


رفتارى در نظر گرفته شود [سب]. نتايج مطالعه حاضر نشان دادند كه مينه نشود مانكين شاخص

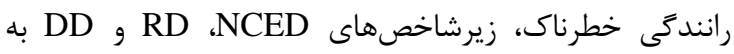

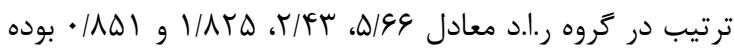

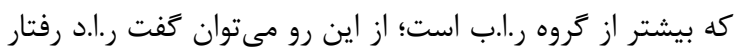

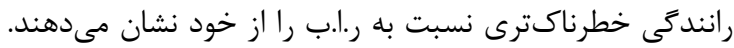

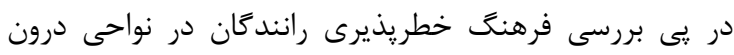

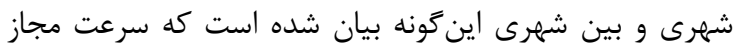
در شهر نسبت به جادهها محدودتر مى باشد؛ در نتيجه، رئ رانندكان نواحى درون شهرى با ترمزهاى ملايمترى (حتى به صورت نيش

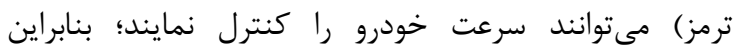

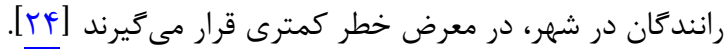


كه سرعت راننده در خيابانهاى شهرى عمدتاً تحت تأثير كنترل ترافيك، محيطهاى خيابانى و تعامل وسايل نقليه قرار

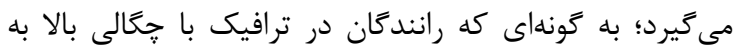

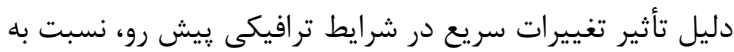



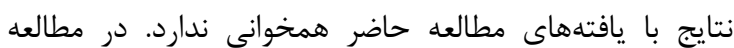
حاضر ميانگين شاخص راندگى خطرناك و زيرشاخصهای مهاى آن 
بى يروا در نظر گرفته شود. اين اقدامات مىتواند شامل: تدوين برنامههاى مداخلهاى براى مديريت ساعت كارى ر رانندگًان

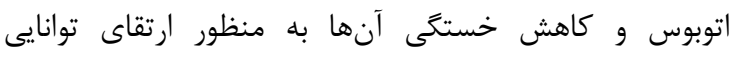

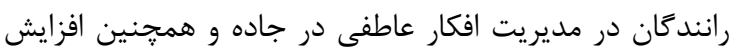

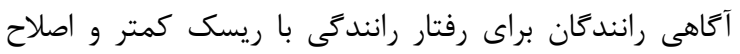
رفتارهاى يرخطر باشد.

\section{تشكر و قدردانى - - مانى}

بدينوسيله نغارندكان اين مقاله از حمايتهاى معاونت

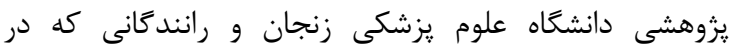
راستاى انجام اين يزوهش با يزوهشكُان همكارى نمودند،

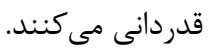

\section{تضاد منافع}

اين مطالعه حاصل بخشى از طرح كميته تحقيقات

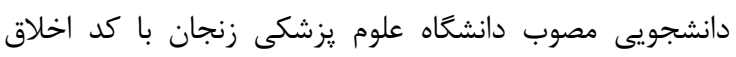

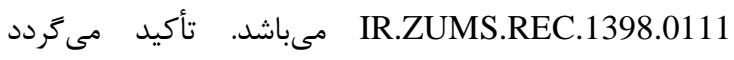
نويسندكان يزوهش حاضر تضاد منافعى با نتايج اين مطالعه

$$
\text { ندارند. }
$$

\section{ملاحظات اخلاقى}

افراد شركت كننده در مطالعه حاضر يس از آشنايى كامل با

اهداف يزوهش و امضاى فرم رضايتنامه آكاهانه وارد مطالعه آنه شدند. شايان ذكر است كه شركت در مطالعه داوطلبانه بود و

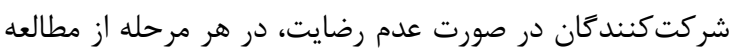

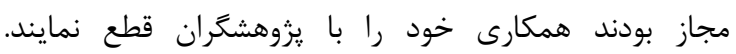

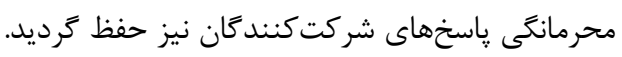

\section{سهم نويسندكان}

در مطالعه حاضر سركار خانم عبدى در گردآروى دادهها و

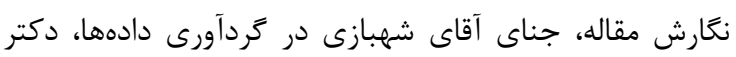


مقاله و اصلاح آن مشاركت داشتند آمارى دكتر آرامي

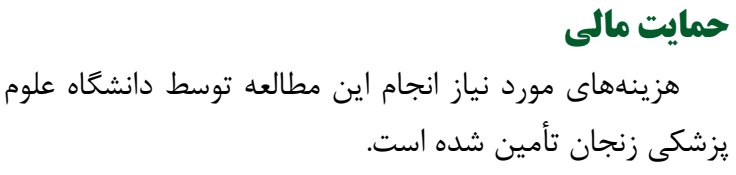

\section{REFERENCES}

1. Fox RT. Examining attention, impulsiveness, and cognitive failures in driving behaviors. Tennessee: East Tennessee State University; 2012.

2. World Health Organization. Global status report on road safety 2018: Summary. Geneva: World Health Organization; 2018.

3. Moafian G, Aghabeigi MR, Hoseinzadeh A, Lankarani KB, Sarikhani Y, Heydari ST. An epidemiologic survey of road traffic accidents in Iran: analysis of driver-related factors. Chin J Traumatol. 2013;16(3):140-4. PMID: 23735547
رانندكان داشته و به نظر مىرسد دليـل ايـن ارتبـاط، خسـتَّى

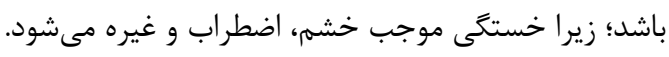

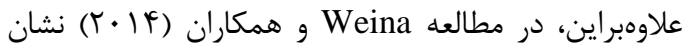

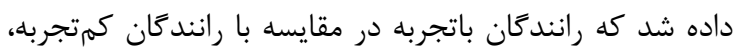
AD و وم وكاران (Yan

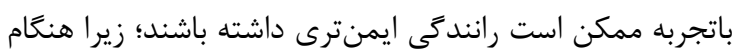

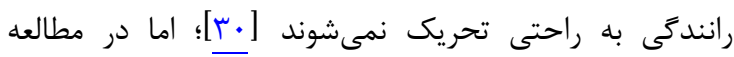

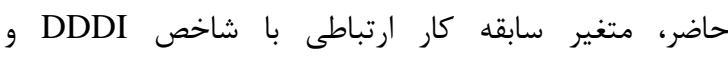
زيرشاخصهاى آن نداشت؛ البته ميانگين سابقه كار ر.ا.ب بيشتر

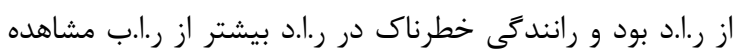

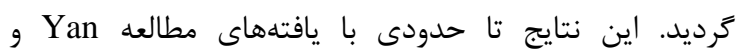
همكاران (Y (Y) همراستا است.

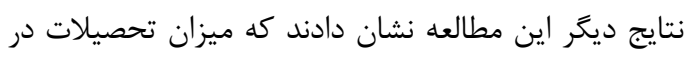



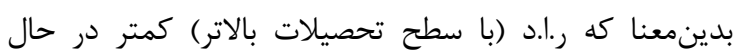
خوابآلودگى و مستى رانندگى مى كردند.

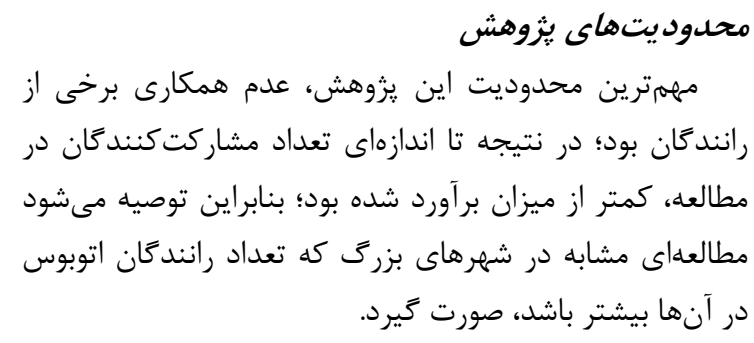
نتيجه كيرى در اين مطالعه نمره DDDI كروه ر.ا.د بيشتر از ر.ا.ب بود؛

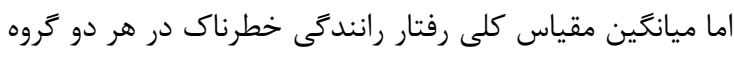

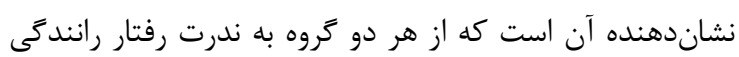

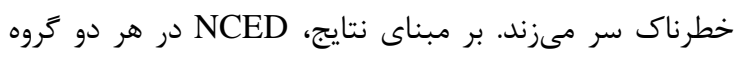



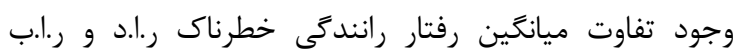

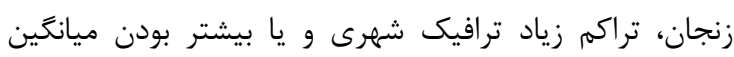

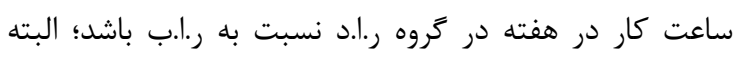

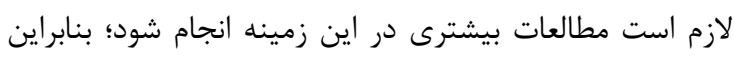

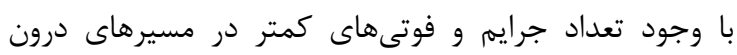

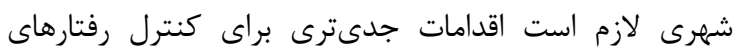

4. Montazeri A. Road-traffic-related mortality in Iran: a descriptive study. Public Health. 2004;118(2):110-3. PMID: 15037040 DOI: $10.1016 / \mathrm{S} 0033-3506(03) 00173-2$

5. Peden M, Scurfield R, Sleet D, Hyder AA, Mathers C, Jarawan E, et al. World report on road traffic injury prevention. Geneva: World Health Organization; 2004.

6. Mansouri Kargar H, Tavakoli Kashani A. Effect of united bus company of Teharan bus drivers behavior on their accident risk based on real data of occurred accidents. Traffic Law Enforcem Res Stud. 2016;1395(16):39-61. 
[Persian]

7. Suhr KA, Dula CS. The dangers of rumination on the road: Predictors of risky driving. Accid Anal Prev. 2017;99:15360. DOI: 10.1016/j.aap.2016.10.026

8. Rohani M, Buhari R. Bus driver: factors that influences behaviour. New York: Semantic Scholar; 2013.

9. Shakerinia I, Mohammadpoor M. Relationship between psychological characteristics mental health, aggression and driving habits in dangerous drivers. J Shahid Sadoughi Univ Med Sci. 2010;18(3):225-33. [Persian]

10. Qu W, Ge Y, Jiang C, Du F, Zhang K. The dula dangerous driving index in China: an investigation of reliability and validity. Accid Anal Prev. 2014;64:62-8. PMID: 24321444 DOI: 10.1016/i.aap.2013.11.004

11. Chimba D, Sando T, Kwigizile V. Effect of bus size and operation to crash occurrences. Accid Anal Prev. 2010; 42(6):2063-7. PMID: 20728663 DOI: 10.1016/j.aap.2010. $\underline{06.018}$

12. Yang J, Peek-Asa C, Cheng G, Heiden E, Falb S, Ramirez $\mathrm{M}$. Incidence and characteristics of school bus crashes and injuries. Accid Anal Prev. 2009;41(2):336-41.PMID: 19245893 DOI: 10.1016/j.aap.2008.12.012

13. Hassanzadeh-Rangi N, Asghar Farshad A, Khosravi Y, Zare G, Mirkazemi R. Occupational cognitive failure and its relationship with unsafe behaviors and accidents. Int $J$ Occup Saf Ergon. 2014;20(2):265-71.DOI: 10.1080/1080 3548.2014.11077051

14. Jafarzadeh B. Accident reduction strategies. The Second Conference of the Safe Society of Tehran, Tehran, Iran; 2008.

15. Moradi A, Rahmani K. Trend of traffic accidents and fatalities in Iran over 20 years (1993-2013). J Mazandaran Univ Med Sci. 2014;24(119):223-34. [Persian]

16. Simons-Morton B, Li K, Ehsani J, Vaca FE. Covariability in three dimensions of teenage driving risk behavior: impaired driving, risky and unsafe driving behavior, and secondary task engagement. Traffic Inj Prev. 2016;17(5):441-6. DOI: 10.1080/15389588.2015.1107183

17. Qu W, Ge Y, Xiong Y, Carciofo R, Zhao W, Zhang K. The relationship between mind wandering and dangerous driving behavior among Chinese drivers. Saf Sci. 2015;78:41-8. DOI: 10.1016/j.ssci.2015.04.016

18. Dula CS, Ballard ME. Development and Evaluation of a Measure of dangerous, aggressive, negative emotional, and risky driving 1. J Appl Soc Psychol. 2003;33(2):263-82.
DOI: 10.1111/j.1559-1816.2003.tb01896.x

19. Najafi S, Arghami S, Khazaee-Pool M. Validity and reliability of the persian version of the dula dangerous driving index. J Health Saf Work. 2020;10(4):416-25.

20. Hernández-Hernández AM, Siqueiros-García JM, RoblesBelmont E, Gershenson C. Anger while driving in Mexico city. PloS One. 2019;14(9):e0223048. PMID: 31568529 DOI: $10.1371 /$ journal.pone.0223048

21. Zanjan. Wikipedia. Available at: URL: fa.wikipedia. org/wiki/ Zanjan; 2016. [Persian]

22. Qu W, Ge Y, Xiong Y, Carciofo R, Zhao W, Zhang K. Dangerous driving in a chinese sample: associations with morningness-eveningness preference and personality. PloS One. 2015;10(1):e0116717. PMID: 25615447 DOI: 10.1371/journal.pone.0116717

23. Zuraida R, Abbas BS. The differences of workload, fatigue, emotional intelligence and driving behavior based on age, experience, time on task per trip among Indonesian intercity bus drivers. Earth Environ Sci. 2020;426(1):012132.

24. Rahimi A, Kazemi M. Drivers risky culture analysis in urban and rural area. Rahvar. 2012;8(16):49-65. [Persian]

25. $\mathrm{Hu} \mathrm{SR}$, Chen SY. Effects of mixed traffic and elderly passengers on city bus drivers' work-related fatigue. Transp Res Part F. 2019;66:485-500. DOI: 10.1016/j.trf.2019.09.020

26. Dorn L, Stephen L, af Wåhlberg A, Gandolfi J. Development and validation of a self-report measure of bus driver behaviour. Ergonomics. 2010;53(12):1420-33. PMID: 21108079 DOI: 10.1080/00140139.2010.532882

27. Ge Y, Qu W, Jiang C, Du F, Sun X, Zhang K. The effect of stress and personality on dangerous driving behavior among Chinese drivers. Accid Anal Prev. 2014;73:34-40. PMID: 25171523 DOI: 10.1016/j.aap.2014.07.024

28. Liu YC, Wu TJ. Fatigued driver's driving behavior and cognitive task performance: Effects of road environments and road environment changes. Saf Sci. 2009;47(8):1083-9. DOI: 10.1016/j.ssci.2008.11.009

29. Miller KA, Filtness AJ, Anund A, Maynard SE, PilkingtonCheney F. Contributory factors to sleepiness amongst London bus drivers. Transp Res Part F. 2020;73:415-24. DOI: $10.1016 /$ j.trf.2020.07.012

30. Ge Y, Zhang Q, Zhao W, Zhang K, Qu W. Effects of trait anger, driving anger, and driving experience on dangerous driving behavior: A moderated mediation analysis. Aggress Behav. 2017;43(6):544-52. PMID: 28556910 DOI: 10.1002/ $\underline{\text { ab. } 21712}$ 